\title{
Numerical investigation on soot particles emission in compression ignition diesel engine by using particulate mimic soot model
}

\author{
Fadzli Ibrahim ${ }^{1,2}$, Wan Mohd Faizal Wan Mahmood ${ }^{1,{ }^{*}}$, Shahrir Abdullah ${ }^{1}$, and Mohd Radzi \\ Abu Mansor ${ }^{1}$ \\ ${ }^{1}$ Department of Mechanical and Materials Engineering, Faculty of Engineering and Built \\ Environment, Universiti Kebangsaan Malaysia, 43600 UKM Bangi, Selangor, Malaysia. \\ ${ }^{2}$ Mechanical and Aerospace Technology Division, Science and Technology Research Institute for \\ Defence (STRIDE), 43000 Kajang, Selangor, Malaysia.
}

\begin{abstract}
Research via computational method, specifically by detailedkinetic soot model offers much more advantages than the simple model as more detailed formation/oxidation process is taken into consideration, thus providing better soot mass concentration, soot size, soot number density as well as information regarding other related species. In the present computational study, investigation of in-cylinder soot concentration as well as other emissions in a single cylinder diesel engine has been conducted, using a commercial multidimensional CFD software, CONVERGE CFD. The simulation was carried out for a close-cycle combustion environment from inlet valve closing (IVC) to exhaust valve opening (EVO). In this case, detailed-kinetic Particulate Mimic (PM) soot model was implemented as to take benefit of the method of moment, instead of commonly implemented simple soot model. Analyses of the results are successfully plotted to demonstrate that the soot size and soot mass concentration are strongly dependent on the detailed soot formation and oxidation process rates. The calculated of soot mass concentration and average soot size at EVO provide the end value of $29.2 \mathrm{mg} / \mathrm{m}^{3}$ and $2.04 \times 10^{-8} \mathrm{~m}$, respectively. Besides, post-processing using EnSight shows the qualitative results of soot concentration along simulation period in the combustion chamber.
\end{abstract}

\section{Introduction}

Fast evolution in diesel engine technology promises a good return in engine performance and efficiency. But stringent emission law in recent times forces diesel engine to be designed not only for superior performance but also with lower emission level. Therefore, particulate emission will still be a hot issue to be debated and solved, so that emissions emitted comply with current law.

One of a major part of particulate matters, soot, definitely gives bad impact not only to the environment but also to human well-being. This undesirable element was reported to cause global warming, acid rain, smog, odors, respiratory and other health hazards [1-4]. A

\footnotetext{
${ }^{*}$ Corresponding author: faizal.mahmood@ukm.edu.my
} 
number of researchers successfully discovered the toxic effect of soot to human health [58] and the cause for a decrease in the overall engine performances [9-12].

Soot, normally in particulate form, was originally formed by the incomplete combustion process. Their details characteristics in terms of physical and chemical properties from their multiple sources - in-cylinder, in exhaust and in-oil, are still continuously explored and deliberated $[13,14]$. Since years ago, investigating soot emission by computational method was become as one of the topics of choice, apart from the experimental method. This method is become more demanding due to its undisputable advantages in terms of time and cost saving. Current development of computer programs with advanced precision of mathematical models brings simulation works closer to the real engine combustion environment.

In conducting soot emission analysis by computational technique, the soot model developed is the most important factor in determining the accuracy level of the analysis. Modeling of soot emissions from diesel engines generally falls into two different approaches: (a) simple empirical models which relate engine operating parameters to soot emissions and (b) complex multi-step phenomenological models that model the individual steps relating to soot formation and oxidation, often also involves complex reaction mechanisms [15]. There are numerous researchers who studied the emissions characteristics by simulation analysis but with various engine parameters using different computer software such as KIVA, Star-CD, OPEN FOAM CFD, AVL FIRE, CONVERGE CFD and also ANSYS FLUENT.

The aim of this study is to investigate the in-cylinder soot formation process within preset engine conditions using detailed soot model, namely Particulate Mimic (PM) model. To accomplish it, a commercial Computational Fluid Dynamic (CFD) software, CONVERGE CFD has been used for detailed computation and analysis purposes while Ensight software has been applied for post-processing technique.

\section{Methodology}

\subsection{Pre-processing setup}

All the engine parameters and combustion conditions are based on a single-cylinder diesel engine, Yanmar TF90M. For simulation purposes, a multidimensional CFD software, CONVERGE CFD which was developed by Convergent Science Inc has been used to simulate combustion environment but limited to the close-cycle combustion which is from inlet valve closing (IVC) at $-168^{\circ}$ Crank Angle (CA) After Top Dead Centre (ATDC) to exhaust valve opening (EVO) at $138^{\circ} \mathrm{CA}$ ATDC.

For accurate geometry model generation, a computer-aided design (CAD) software, Unigraphic NX 10.0, was used as shown in Figure 1. It was then exported to the preprocessing software, CONVERGE CFD for the geometry checking and clean-up [16] as shown in Figure 2. 

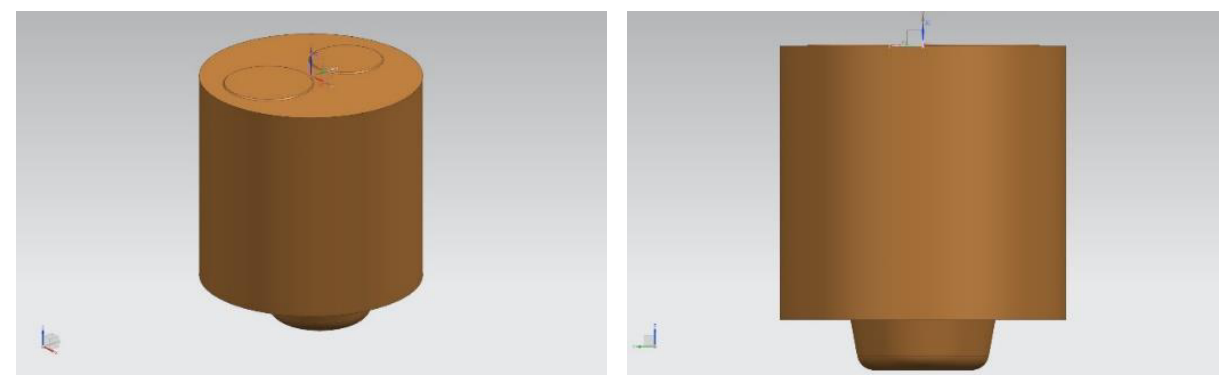

Fig. 1. Model of the combustion chamber created by Unigraphic NX 10.0.

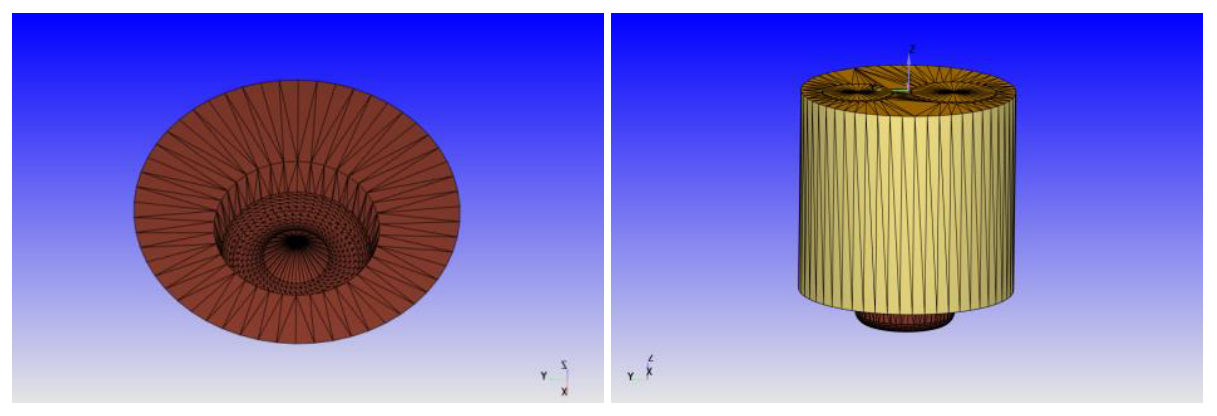

Fig. 2. Model of the combustion chamber cleaned-up by CONVERGE CFD.

Figure 3 shows the schematic diagram of the full combustion chamber complete with bowl-in-piston configuration. The details specification of the engine, operating conditions, initial conditions and fuel model used in the simulation are shown in Table 1, Table 2, Table 3 and Table 4. In the current test cases, no exhaust gas recirculation (EGR) was employed.



Fig. 3. Combustion chamber with piston bowl diagram. 
Table 1. Test engine specification.

\begin{tabular}{cc}
\hline Parameters & Specifications \\
\hline Engine make & Yanmar TF90M \\
Engine type & Water-cooled 4 cycle Diesel engine \\
Engine capacity $(\mathrm{cc})$ & 493 \\
Number of cylinder & 1 \\
Bore $\times$ Stroke & $85 \times 87 \mathrm{~mm}$ \\
Injection system & Direct injection \\
Injection nozzle $(\mathrm{n} \times \varnothing \mathrm{d})$ & $4 \times \varnothing 0.22 \mathrm{~mm}$ \\
Compression ratio & $18.0: 1$ \\
\hline
\end{tabular}

Table 2. Engine operating condition.

\begin{tabular}{cc}
\hline Parameters & Specifications \\
\hline Engine speed & $1600 \mathrm{rpm}$ (max. torque) \\
Initial Swirl ratio (assumed) & 1.8 \\
Start of Injection (SOI) & $-18^{\circ}$ ATDC \\
Injection period (assumed) & $15^{\circ}$ \\
Injection pressure & $196 \mathrm{bar}$ \\
Injection quantity & $19 \mathrm{mg}$ \\
Injection profile & Single main injection \\
\hline
\end{tabular}

Table 3. Engine initial conditions (assumed).

\begin{tabular}{cc}
\hline Parameters & Specifications \\
\hline In-cylinder temperature & $315 \mathrm{~K}$ \\
In-cylinder pressure & $105 \mathrm{KPa}$ \\
Piston Head temperature & $363 \mathrm{~K}$ \\
Cylinder Liner temperature & $319 \mathrm{~K}$ \\
Piston temperature & $403 \mathrm{~K}$ \\
\hline
\end{tabular}

Table 4. Fuel specification.

\begin{tabular}{cc}
\hline Parameters & Specifications \\
\hline Fuel model & Diesel Euro5M \\
Density @ $15^{\circ} \mathrm{C}$ & $832.2 \mathrm{Kg} / \mathrm{m}^{3}$ \\
\hline
\end{tabular}

\subsection{Mesh setup}

One of the aims in conducting this computational analysis is having full flexibility in mesh setup. By applying the extra feature embedded in CONVERGE CFD software so-called Adaptive Mesh Refinement (AMR), the computational time could be reduced significantly, instead of conventional setting with the similar mesh size for the whole simulation. This feature allows users to refine mesh size accordingly to certain spatial and temporal conditions. In this study, the overall mesh resolution of $1.0 \mathrm{~mm}$ was found to sufficiently produce grid independent results, as the comparison of different mesh size shown in Figure 4. This mesh size was resulted in 624,556 elements at the time when the intake valve closes. Injector region that was assumed as the most essential segment was set to $0.25 \mathrm{~mm}$ of mesh size. But it will only be activated during AMR feature which in this case starts from $-18^{\circ} \mathrm{CA}$ onwards. 


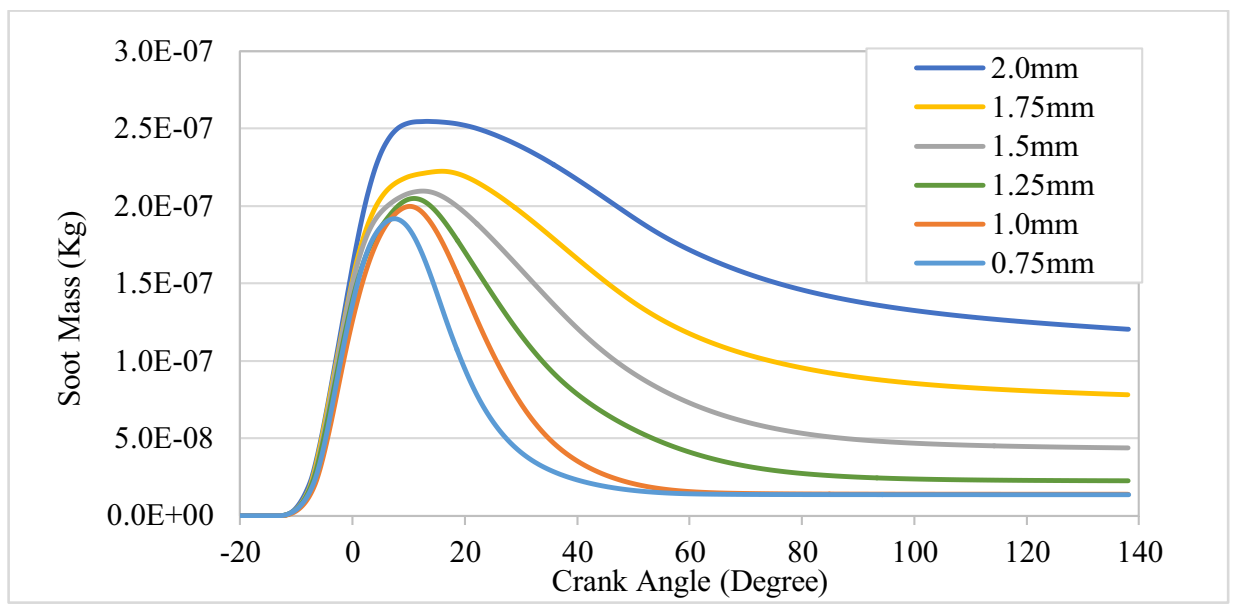

Fig. 4. Soot mass comparison for different mesh size.

Figure 5 shows the difference of mesh setting according to spatial and temporal condition with regard to AMR setup.

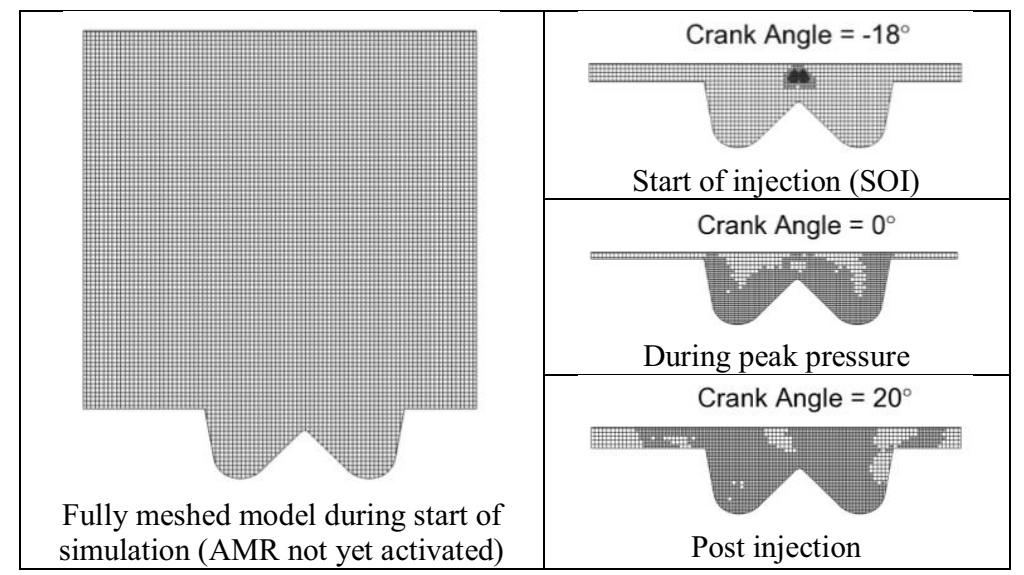

Fig. 5. The diagram of the meshed model during start of the simulation, follow by the difference of mesh condition with regard to AMR setup.

\subsection{Processing setup}

Despite of typically used two-steps soot model, a more detailed soot model, Particulate Mimic (PM) which based on the method of moments was applied. Via this model, all the basic physical and chemical processes for the formation of soot are measured which are particle inception, coagulation, condensation, surface growth and oxidation $[17,18]$. The dynamics of the soot particle characteristics can be described by following equations [16];

$$
\frac{d M_{r}}{d t}=\dot{M}_{r, p i}+\dot{M}_{r, c o n}+\dot{M}_{r, c o a g}+\dot{M}_{r, s g}-\dot{M}_{r, o x}
$$


where $\dot{M}_{r, p i}, \dot{M}_{r, c o n}, \dot{M}_{r, \text { coag }}, \dot{M}_{r, s g}$ and $\dot{M}_{r, o x}$ are the rates of particle inception, condensation, coagulation, surface growth and oxidation for the $r^{\text {th }}$ moment of the particle size distribution function (PSDF), respectively. The moments can be defined as;

$$
M_{r}=\sum_{i=1}^{\infty} i^{r} N_{i}
$$

where $N_{i}$ is the number density of soot particles of size class $i$.

As part of diesel fuel, only n-heptane $\left(\mathrm{C}_{7} \mathrm{H}_{16}\right)$ will be considered as a fuel species for further analysis, acetylene $\left(\mathrm{C}_{2} \mathrm{H}_{2}\right)$ as a formation species, $\mathrm{OH}$ and $\mathrm{O}_{2}$ as the oxidation species, and soot density is assumed to be $1.84701 \mathrm{~g} / \mathrm{cm}^{3}$ [19]. All these chemical species will be used to model diesel combustion chemistry based on Zeuch mechanism [20], producing a total of 588 reaction mechanism which contains of 5 elements and 121 species. Additional species of $\mathrm{A}_{3} \mathrm{R}_{5 \text { - }}$ as a soot precursor is set for the detailed soot model. In addition to the soot model, other dedicated sub-models are used to solve each sub-process, including spray breakup, turbulence and combustion. These sub-models are listed in Table 5.

Table 5. The computational sub-models applied.

\begin{tabular}{cc}
\hline Phenomenon & Model \\
\hline Soot formation & PM model based on method of moment $[17,18]$ \\
NOx formation & Extended Zeldovich [21] \\
Spray breakup & KH-RT model $[22,23]$ \\
Drop drag & Dynamic model [24] \\
Collision and coalescence & NTC model [25] \\
Spray-wall interaction & Rebound/slide model [26,27] \\
Vaporization & Multi component fuel \\
Turbulence & RNG k- $\mathcal{E}$ model [28] \\
Combustion & SAGE [29] \\
\hline
\end{tabular}

All the computational models are then executed using CONVERGE CFD as a solver, and the results are visualized using post-processing software, EnSight 10.1. This postprocessor software was used to animate or visualize the complex datasets obtained from computational analyses [30]. All the executed results of soot and other gas emissions characteristics are presented in the next section.

\section{Results and discussion}

\subsection{Temperature and pressure effects}

Reaction rates for both soot formation and oxidation process are strongly dependent on pressure and temperature effect. While these two factors are increased, the rate of oxidation increases more rapidly than the rate of formation [31]. As to show the relevance to the sooting process, changes of the pressure and temperature along the simulation time are plotted and shown in Figure 6. 


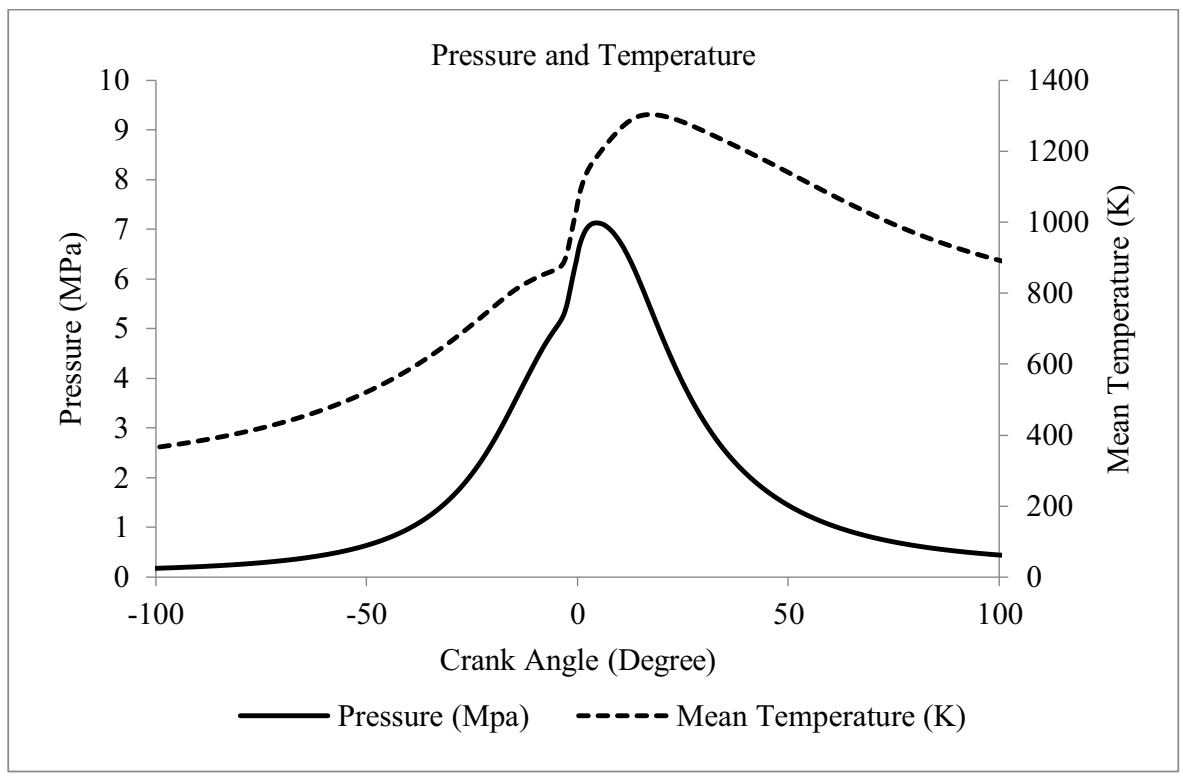

Fig. 6. Temperature and pressure change in the simulation.

The pressure and temperature value at IVC were set to $0.105 \mathrm{MPa}$ and $315 \mathrm{~K}$ respectively, as an initial in-cylinder condition. As the piston moving upward during the compression stroke, these two values keep increasing until their maximum limit of 7.13 $\mathrm{MPa}$ at $4.5^{\circ} \mathrm{CA}$ for pressure and $1303.47 \mathrm{~K}$ at $17.3^{\circ} \mathrm{CA}$ for temperature. So the value of soot concentration which will be described in the subsequent section is strongly influenced by these parameters.

\subsection{Soot concentration}

Based on Eq. 1 and Eq. 2, soot mass concentration is plotted as shown in Figure 7. PM soot model calculates the soot formation since early of simulation time even with very tiny soot mass concentration value at $1.92 \times 10^{-15} \mathrm{mg} / \mathrm{m}^{3}$. The value from PM model however gradually increases to the peak value of $655.83 \mathrm{mg} / \mathrm{m}^{3}$ at $16.3^{\circ} \mathrm{CA}^{\circ}$ before decreases to the end value of $29.2 \mathrm{mg} / \mathrm{m}^{3}$. As reported by Symonds et. al (2007) [32], the experimental values from Diesel Particulate Filter (DPF) and Diesel Mobility Spectrometer (DMS) fell within the range of $20.5 \mathrm{mg} / \mathrm{m}^{3}$ to $67.7 \mathrm{mg} / \mathrm{m}^{3}$, as shown at end of simulation in Figure 7 . So the end computed value from simulation was well agreed with the experimental value.

PM as a detailed soot model considers all the important process in sooting formation, i.e. nucleation, fragmentation, surface growth, condensation, coagulation and oxidation, as compared to simpler soot model, i.e. Hiroyasu's soot model, which only considers soot formation and oxidation process only in general form. As to confirm whether this value of soot mass complies with the current emission regulation, the end value at EVO which assumed to be the mass that will be emitted to the atmosphere through the exhaust pipe should be converted into a comparable unit with emission regulation values. 


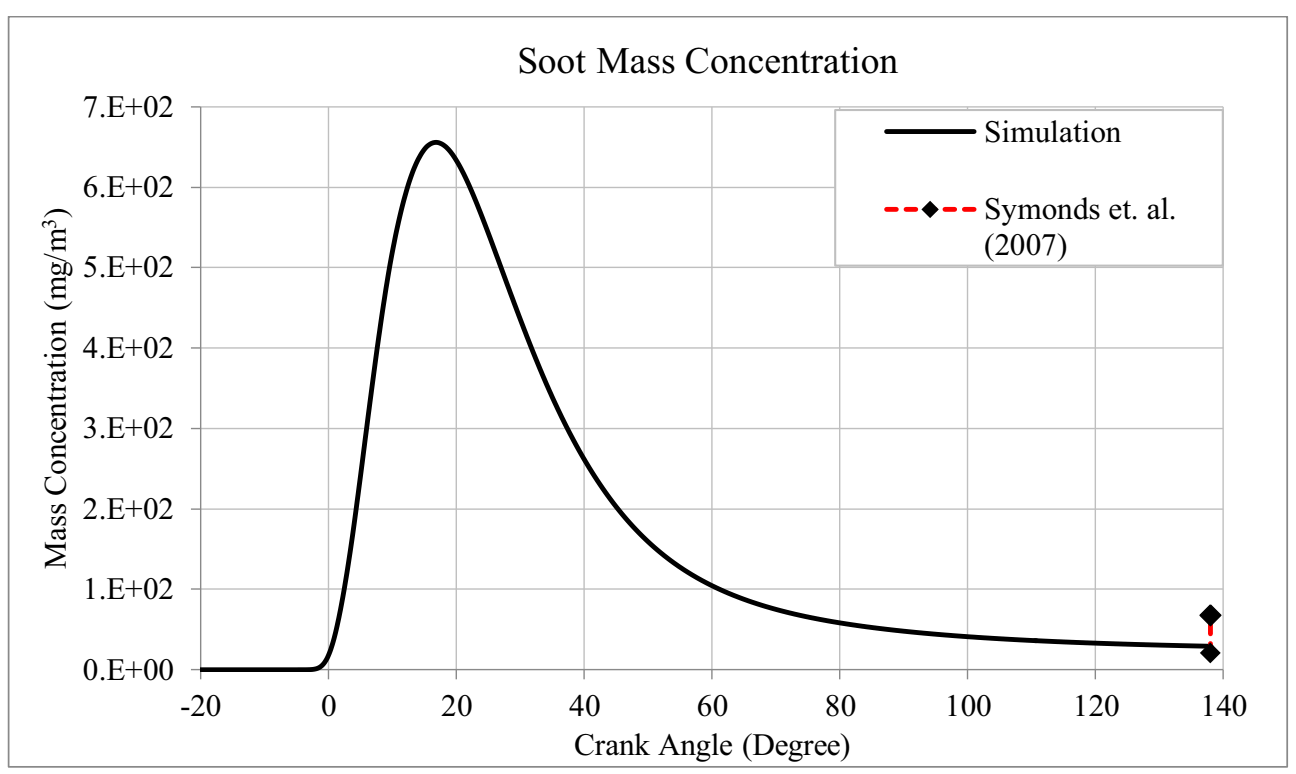

Fig. 7. Soot mass concentration of PM soot model.

Another extra parameter provided by PM soot model is soot average diameter, which is not calculated by the simple model. Initial soot size plotted was $8.66 \times 10^{-10} \mathrm{~m}$ and keeps increasing until its final value of $2.04 \times 10^{-8} \mathrm{~m}$ at EVO. This final value was perfectly agreed with the average soot size as suggested by Giechaskiel et. al. (2014) [33] which reported the values were fall within $10 \mathrm{~nm}$ to $30 \mathrm{~nm}$. The average soot diameter is plotted and shown in Figure 8. The rapid increment of this value is principally due to relatively higher surface growth rate than oxidation rate. Similar to soot mass value, the information of soot size is also essential to comply with the current emission regulations.

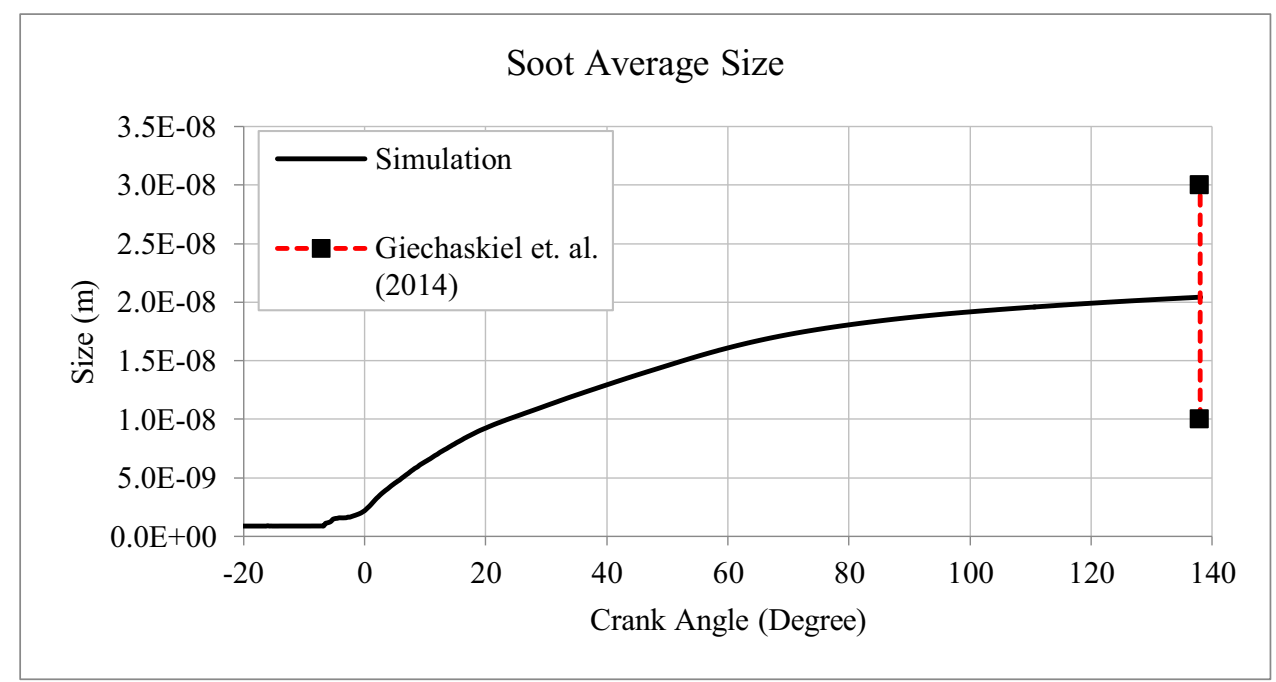

Fig. 8. Average soot diameter by PM soot model. 
Using EnSight 10.1 as a post-processor, the net soot mass concentration on a crosssectional plane of the combustion chamber can be visualized as presented in Figure 9. Soot mass concentration plotted from early injection period until end of the simulation are consistent with the net soot mass shown in Figure 7 during combustion process. Additionally, this qualitative result clearly presented that particles with higher mass value are more concentrated at the lower part of the cylinder (i.e. squish/bowl region) instead of the upper side of the cylinder. Towards the end of simulation, almost all of the particles with lower soot mass value occupies the upper side and near the cylinder wall, and these lighter soot particles are assumed to be emitted during exhaust stroke while a part of it will remain and deposited onto the cylinder wall.

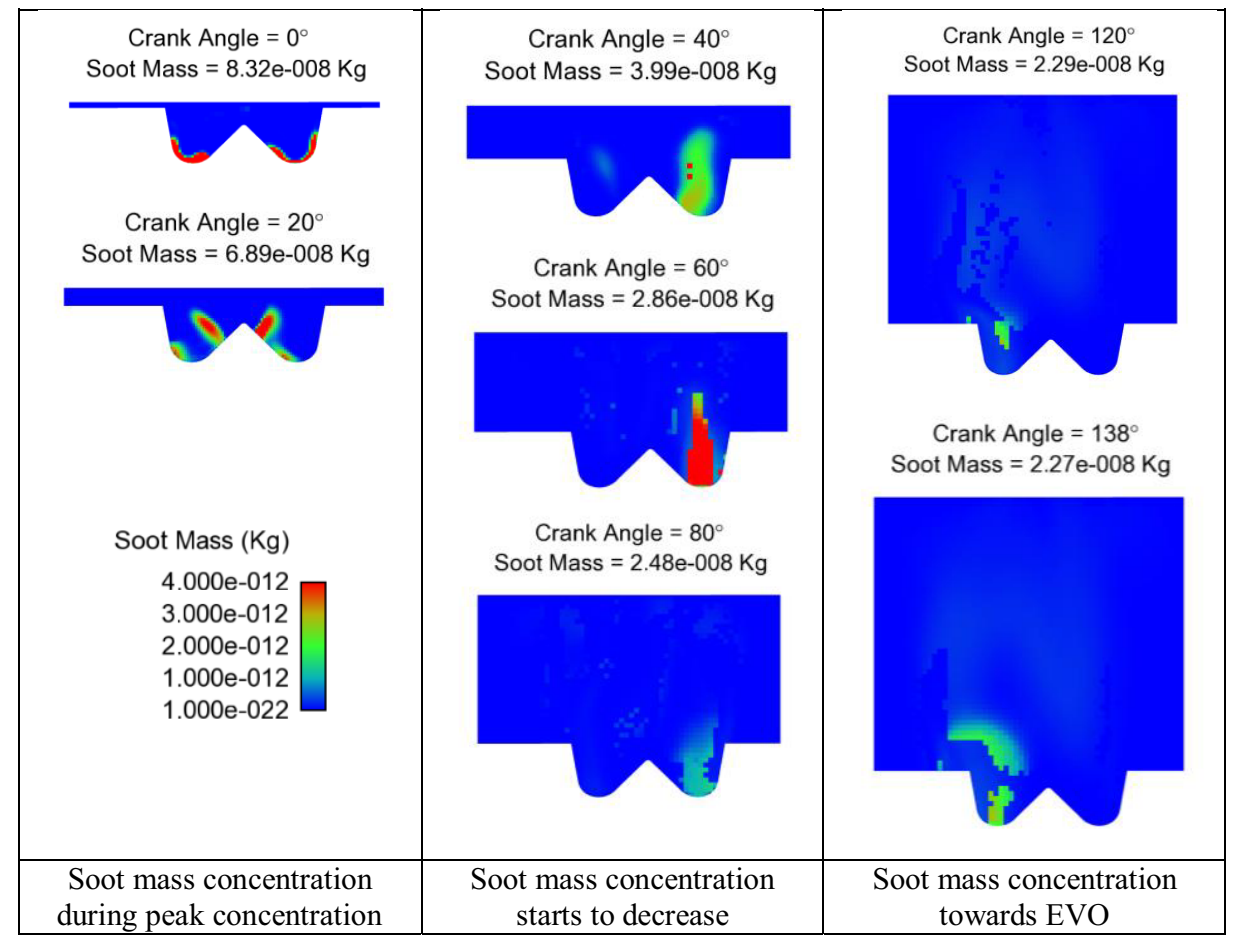

Fig. 9. Soot mass concentration in the combustion chamber.

\section{Conclusions}

In conducting soot emission analysis by computational technique, applying more complex soot model will give more advantages than simpler or most commonly applied two-step soot model. This study applied PM soot model, which is based on the method of moments as a detailed model. The calculated of soot mass concentration at EVO shows decreasing value from peak to the end value of $29.2 \mathrm{mg} / \mathrm{m}^{3}$. Average soot size was recorded to keep increasing since early in the simulation, at the start of combustion, until its final value of $2.04 \times 10^{-8} \mathrm{~m}$ at EVO. All the data obtained are strongly related to each of soot formation and oxidation process rates. All those values are well agreed with the suggested values as reported by some researchers through their experimental activities, thus suggesting that the PM soot model was well configured and the results are acceptable to almost similar actual combustion environment. 
Further qualitative analysis by post-processing software demonstrates that soot mass concentration pattern is comparable with calculated value. It is demonstrated that heavier soot particles are more concentrated at the lower part of the cylinder (squish/bowl region) instead of the upper side of the cylinder. Until the end of simulation, lighter soot particles which occupy the upper side of the cylinder are expected to either move out through exhaust manifold or deposited onto the cylinder wall.

Nowadays, development of CFD software in simulating the engine combustion phenomenon with higher complexity has become more advanced, thus allowing more detailed soot model to be analyzed in more efficient ways. In order to endorse the results from this simulation method, validation by real combustion event through experimental work will remain an important criterion which is planned to be performed in the next future. Overall, CONVERGE-CFD software provides a good opportunity for soot particle study by various soot models.

The authors would like to acknowledge the support from Ministry of Higher Education of Malaysia through its research grant of FRGS/1/2013/TK01/UKM/02/2. All the funding is well translated by Department of Mechanical and Materials Engineering, Faculty of Engineering and Built Environment, Universiti Kebangsaan Malaysia (UKM) for its beneficial uses. The authors are pleased to acknowledge Public Service Department support for Fadzli Ibrahim through the HLP Programme. Special thanks to STRIDE for granting the use of its facilities regarding to this project.

\section{References}

1. V. Ganesan, Internal Combustion Engines (McGraw-Hill, 2004).

2. P. Eastwood, Particulate Emissions from Vehicles (John Wiley \& Sons, 2008).

3. W.W. Pulkrabek, Engineering Fundamentals of the Internal Combustion Engine (Pearson Prentice Hall, 2004).

4. M.F.Gómez-Rico, I. Martín-Gullón, A. Fullana, J.A. Conesa, R. Font. J. Anal. Appl. Pyrolysis 68-69, 527-546 (2003).

5. B. Brunekreef, S.T. Holgate. Lancet. 360, 1233-1242 (2002).

6. J. Kagawa. Toxicology. 181-182, 349-353 (2002).

7. N. Englert. Toxicol. Lett. 149, 235-242 (2004).

8. K. Kim, E. Kabir, S. Kabir. Environ. Int. 74, 136-143 (2015).

9. G. Woschni, K. Huber. SAE Tech. Pap. No. 910297 1-8 (1991).

10. R. Mainwaring. SAE Tech. Pap. No. 971631 47-64 (1997).

11. S. George, S. Balla, M. Gautam. Wear. 262, 1113-1122 (2007).

12. S. George, S. Balla, V. Gautam, M. Gautam. Tribol. Int. 40, 809-818 (2007).

13. F. Ibrahim, W.M.F. Wan Mahmood, S. Abdullah, M.R. Abu Mansor. Def. S\&T Tech. Bull. 8, 141-152 (2015).

14. F. Ibrahim, W.M.F. Wan Mahmood, S. Abdullah, M.R. Abu Mansor. ReCAR 2015 (2015).

15. I.M. Kennedy. Prog. Energy Combust. Sci. 23, 95-132 (1997).

16. K.J. Richards, P.K. Senecal, E. Pomraning. CONVERGE (v2.2.0). (Convergent Science Inc. 2014).

17. A. Kazakov, M. Frenklach. Combust. Flame 114, 484-501 (1998).

18. M. Frenklach, H. Wang. Twenty-Third Symp. Combust., 1559-1566 (The Combustion Institute, 1990).

19. M.Y. Choi, A. Hamins, G.W. Mulholland, T. Kashiwagi. Combust. Flame. 99, 174186 (1994).

20. T. Zeuch, G. Moréac, S.S. Ahmed, F. Mauss. Combust. Flame. 155, 651-674 (2008).

21. J. B. Heywood. Internal Combustion Engine Fundamentals. (USA, 1988). 
22. R.D. Reitz, F.V. Bracco. Encycl. Fluid Mech., (Gulf Pub. 1986).

23. L.M. Ricart, J. Xin, G.R. Bower, R.D. Reitz. SAE Tech. Pap. No. 971591. 13-31 (1997).

24. A.B. Liu, D. Mather, R.D. Reitz. SAE Tech. Pap. Ser. No. $930072.1-13$ (1993).

25. D.P. Schmidt, C.J. Rutland. J. Comput. Phys. 164, 62-80 (2000).

26. J.D. Naber, R.D. Reitz. SAE Tech. Pap. Ser. No. 880107. 1-23 (1988).

27. M.A. González, Z.W. Lian, R.D. Reitz. SAE Tech. Pap. Ser. No. 920579. 1-13 (1992).

28. Z. Han, R.D. Reitz. Combust. Sci. Technol. 106, 267-295 (1995).

29. P.K. Senecal, E. Pomraning, K.J. Richards, T.E. Briggs, C.Y. Choi, R.M. McDavid, M.A. Patterson. SAE Tech. Pap. 2003-01-1043 (2003).

30. Computational Engineering International Inc. EnSight User Manual for version 10.1. (Computational Engineering International, Inc. 2013).

31. D.R. Tree, K.I. Svensson. Prog. Energy Combust. Sci. 33, 272-309 (2007).

32. J.P.R. Symonds, K.S. Reavell., J.S. Olfert, B.W. Campbell, S.J. Swift. J. Aerosol Sci. 38, 52-68 (2007).

33. B. Giechaskiel, M. Maricq, L. Ntziachristos, C. Dardiotis, X. Wang, H. Axmann, A. Bergmann, W. Schindler. J. Aerosol Sci. 67, 48-86 (2014). 